\title{
Quality of Life, Perception of Disease and Coping Strategies in Patients with Hemophilia in Spain and El Salvador: A Comparative Study
}

\author{
Rubén Cuesta-Barriuso (D) 1,2 \\ Ana Torres-Ortuño iD ${ }^{3}$ \\ Joaquín Nieto-Munuera ${ }^{3}$ \\ José Antonio López-Pina (D) ${ }^{4}$ \\ 'Department of Physiotherapy, University \\ of Murcia, Murcia, Spain; ${ }^{2}$ Royal Victoria \\ Eugenia Foundation, Madrid, Spain; \\ ${ }^{3}$ Department of Psychiatry and Social \\ Psychology, University of Murcia, Murcia, \\ Spain; ${ }^{4}$ Department of Basic Psychology \\ and Methodology, University of Murcia, \\ Murcia, Spain
}

Background: Hemophilia is characterized by the development of joint bleeds that cause long-term joint damage (hemophilic arthropathy). Joint damage leads to disability and affects psychosocial aspects in patients with hemophilia.

Objective: To compare the clinical situation, perception of disease and quality of life, and coping strategies in adult patients with hemophilia in El Salvador and Spain.

Methods: In this comparative clinical study, 43 patients with hemophilia aged between 18 and 50 years old from Spain and El Salvador participated. After obtaining the patients' consent, they completed the Illness Perception Questionnaire-Revised (IPQ-R), HemophiliaQoL and Inventory of Coping strategies questionnaires. Joint status was assessed using the Hemophilia Joint Health Score and based on a record of clinical and treatment data.

Results: Hemophilia patients from Spain showed an improved perception of quality of life $(p<0.05)$, although there were only differences in the self-criticism variable $(p=0.04)$ for coping strategies. Joint damage and age correlated $(\mathrm{p}<0.05)$ negatively with perception of disease, perceived quality of life and coping strategies in both populations. There were differences $(p<0.05)$ between the two populations based on HIV and HCV coinfections in perception of disease and perceived quality of life.

Conclusion: Patients with hemophilia in El Salvador exhibit a poorer perception of disease and quality of life. Despite differences in access to treatment from one country to the other, there is no difference in coping with the disease. Older patients are better able to adapt to the disease.

Keywords: hemophilia, joint disease, quality of life, illness perception, coping strategies

\section{Introduction}

Hemophilia is a congenital coagulation disorder that presents a lack of some of the clotting factors (FVIII in hemophilia A and FIX in hemophilia B). This pathology is characterized by bleeding episodes, mainly in the locomotor system. Most bleeding occurs in the joints (hemarthrosis). ${ }^{1}$ The recurrence of joint bleeding causes changes in the synovial membrane (chronic synovitis) and joint structure, leading to intra-articular alterations and functional limitations. ${ }^{2}$

When a joint is repeatedly affected by hemarthrosis, the inactivity associated leads to atrophy of the periarticular muscles and joint instability. This process progressively entails irreversible joint degeneration and the development of chronic hemophilic arthropathy, characterized by joint deformity, functional limitations, disability, chronic pain, and a poorer perception of quality of life. ${ }^{3}$
Correspondence: Rubén Cuesta-Barriuso Department of Physiotherapy, University of Murcia, Campus Espinardo, Murcia, 30200 , Spain

$\mathrm{Tel}+34868887286$

Email ruben.cuestab@gmail.com 
Regular administration of clotting factor concentrates (prophylaxis) is the most effective treatment to prevent bleeding and disability in patients with hemophilia. ${ }^{4}$ The development of antibodies against the treatment with clotting factor concentrates (inhibitors) is the main clinical complication in these patients, increasing the rate of musculoskeletal sequelae. $^{5}$

In the 1950's, fresh frozen plasma was the therapeutic option for patients with hemophilia worldwide, regardless of the economic development of the country. ${ }^{6}$ The emergence of Cryoprecipitate in 1965 made available an effective treatment to address bleeding episodes. ${ }^{7}$ However, since the $70 \mathrm{~s}$, factor concentrates became more widely available, allowing a more effective treatment to control hemorrhages. ${ }^{8}$

The high incidence of infections due to the human immunodeficiency virus (HIV) and Hepatitis C virus $(\mathrm{HCV})$ in the $80 \mathrm{~s}$, prompted the development of new safer factor concentrates. This increased the differences between countries in the accessibility to new treatments, based on their higher or lower economic resources. ${ }^{9}$

The life expectancy of hemophiliacs living in developed countries is similar to that of the general population, in view of the new treatments developed..$^{10}$ However, $75 \%$ of patients living in developing countries have no access to the more modern treatments, and therefore their life expectancy is considerably lower. ${ }^{11}$

The promotion of associationism and training of the leaders of the National Hemophilia Organizations, together with Government commitment, has enabled patients to access the new treatments, with an increased life expectancy, reaching adulthood with fewer joint sequelae and ultimately enjoying an improved quality of life. ${ }^{12}$

The World Federation of Hemophilia has recently been developing programs to raise the awareness of national governments and twinning programs between developed and developing countries, with the aim of improving in the latter the therapeutic approach to patients with hemophilia. ${ }^{13,14}$

In order to assess the quality of life of the patients, not only their physical condition but also their own perception and assessment thereof need to be considered. Quality of life, and specifically health-related QoL, refers to the subjective perception of the individual of how their health influences their general functioning and promotes the achievement of their projects and goals, reflecting on their level of well-being. ${ }^{15}$ It is essential to consider objective health aspects, but at the same time account for other psychosocial factors such as: beliefs, attributions and meanings that greatly condition a patient's response to the disease.

One of the models used to establish how the subject develops these beliefs and how they affect adapting to the disease is the Common-Sense model of SelfRegulation. ${ }^{16,17}$ This model proposes that subjects conduct a parallel processing of the emotional and cognitive representations of their illness, and their coping possibilities.

Studies conducted in hemophilia seem to confirm that health status assessment is affected by the subject's representations of their illness. ${ }^{18,19}$ In addition, they argue that no causal or direct relationship has been found between poor health and negative emotions, owing to coping strategies or psychological defense mechanisms employed. This is consistent with what was pointed out by Reynolds et al, ${ }^{20}$ whereby a good perception of the disease reflects an effective management thereof.

To cope with or solve problematic circumstances, a good medical treatment and psychological resources or strategies used are equally important. ${ }^{21,22}$ In general, there are two forms of coping: problem-oriented and emotionoriented. In chronic diseases, the problem-oriented strategy is considered the most effective and adaptive strategy, while the emotion-oriented strategy is a resource for more acute situations. ${ }^{23,24}$

The study on coping in patients with hemophilia has barely been addressed. Most research focuses on the parents of the affected children ${ }^{25,26}$ or on coping with the pain or limitations caused by hemophilia. ${ }^{27,28}$ Binnema and $\operatorname{Brodin}^{29,30}$ found that adult patients, regardless of their state of health, often cope positively, while stressing on the importance of assessing the psychological aspects that influence how individuals cope with hemophilia.

The aim of this study is to compare two populations of patients with hemophilia, from El Salvador and Spain, analyzing the clinical situation, perception of disease and quality of life, and coping strategies employed.

\section{Materials and Methods Study Design}

Comparative study of adult patients with hemophilia from El Salvador and Spain, where access to treatment and the approach of hemophilia differ greatly.

\section{Selection Criteria}

The criteria for inclusion in this study were patients: over 18 years old, with a diagnosis of hemophilia $\mathrm{A}$ and $\mathrm{B}$, with 
severe or moderate phenotype, having signed the informed consent document, without cognitive disorders that impede oral and written comprehension of the questionnaires. Patients excluded were those with a diagnosis of another congenital coagulopathy (for example, von Willebrand disease), having undergone surgery in the 12 months preceding the study and those presenting cognitive disorders or failing to complete the questionnaires. Patients who at the time of the study had antibodies to clotting factor concentrates (inhibitors) were also included in the study.

\section{Ethical Considerations}

The study was approved by the Ethics Committee of the University of Murcia. All patients were informed of the study objectives and signed the consent document in accordance with the Helsinki agreement on clinical trials.

\section{Patients}

In the framework of the Twinning Program of the Fundación Novo Nordisk in El Salvador, patients with hemophilia treated at the University Hospital of San Salvador were summoned. Of the 47 patients attending the training program, 28 were adults. Twenty-two met the inclusion criteria (two were excluded for having a diagnosis of factor $\mathrm{V}$ deficit, two for having a severe cognitive disease that prevented the evaluation and two because they had undergone open synovectomy in the months preceding the study).

The Spanish sample was recruited from among associations of hemophiliacs from different regions of Spain. Thirty-four patients initially agreed to participate in the study and 21 ultimately met the inclusion criteria (five were excluded due to a diagnosis of von Willebrand disease; one with a severe cognitive disease that prevented the evaluation; three for developing hemarthrosis the week prior to the study; and four because they had undergone open orthopedic knee surgery in the months preceding the study).

\section{Measuring Instruments}

The dependent variables evaluated in this study are perception of disease, quality of life, and coping strategies. Measuring instruments used to assess these variables were:

\section{Perception of Disease}

Illness Perception Questionnaire-Revised (IPQ-R) was used $^{31}$ based on Leventhal's Common-Sense model. It evaluates the representation of the disease in patients with hemophilia. It consists of eight dimensions: Identity, Consequences, Personal control, Treatment control, Illness coherence, cycles of Illness and emotional representation.

\section{Perception of Quality of Life}

The Hemophilia-QoL questionnaire was used. ${ }^{32}$ It evaluates the quality of life in patients with hemophilia. It consists of 36 items that rate nine dimensions of quality of life: physical health, daily activities, joints, pain, satisfaction with treatment, treatment difficulties, emotional functioning, mental health and relationships and social activity.

\section{Coping Strategies}

The Coping Strategies Inventory was employed. ${ }^{33}$ It evaluates coping strategies used by the subject in the stressful situation posed by the disease ( 40 items on a 5 -point Likert scale). It has eight scales (problem solving, cognitive restructuring, social support, emotional expression, avoidance of problems, desiderative thinking, social withdrawal and self-criticism).

In addition, clinical data were recorded to obtain the patients' main anthropometric characteristics and clinical characteristics (hemophilia type and severity, medical treatment scheduled, and dosage of FVIII/FIX concentrates). Finally, the clinical data of joint damage in the patients were collected, using the Hemophilia Joint Health Score-HJHS. ${ }^{34}$ This scale assesses the degree of joint deterioration as a result of hemophilia arthropathy on a scale of 0 to 20 points per joint ( 0 represents no damage, while 20 represents maximum joint damage).

\section{Statistical Analysis}

The statistical analysis was carried out using the statistical package SPSS 19.0 for Windows (IBM Corporation, Somers, NY, USA). A descriptive analysis of the patients who participated in the study was performed. The Student's $t$-test and ANOVA were used to analyze differences depending on the group. Correlations were obtained between study-dependent variables and independent quantitative and qualitative variables, respectively. A 95\% level was established for the estimation of the Confidence interval (CI).

\section{Results}

Forty-three patients with hemophilia from both countries participated in the study. Twenty-two patients were from El Salvador and 21 patients from Spain. The mean age of 
the sample from El Salvador was 29.36 (SD: 8.31). All patients had hemophilia A, $86.4 \%$ with a severe phenotype, and $100 \%$ were on demand treatment (without home treatment). The mean age of the Spanish sample was 34.19 (SD: 9.73). Most of the patients had hemophilia A (90.5\%), severe phenotype (71.4\%) and was on demand treatment $(76.2 \%)$. All HIV patients in both populations exhibited an undetectable viral load. While all HCV patients from El Salvador presented an active HCV infection, only two patients from the Spanish population evolved to recovery from hepatitis $\mathrm{C}$ infection. Regarding joint damage, significant differences were found between the two groups, with greater joint damage in the patients from El Salvador (Table 1).

When comparing the two populations, we found significant differences $(p<0.01)$ in the perception of disease in Consequences, Disease cycle and Emotional representation. A comparison of perception of quality of life disclosed significant differences $(p<0.01)$ in all the items, except in Satisfaction with the treatment $(p=0.13)$. With regard to coping strategies, there were only differences in the Self-criticism item $(p=0.04)$ (Table 2).

There was a negative correlation in the Spanish simple between joint damage and perception of disease (Cycles of illness; $p<0.05$ ), the perception of quality of life (Physical health and Satisfaction with the treatment; $p<0.05$ ) and coping strategies (Problem solving; $\mathrm{p}<0.05$ ). A negative correlation existed between age and perception of illness (Cycles of illness; $p<0.01$ ) and coping strategies (Problem solving; $\mathrm{p}<0.05$ ). The sample from El Salvador exhibited a positive correlation between joint damage and coping strategies (Emotional expression; $\mathrm{p}<0.05$ ). For its part, age correlated negatively with perception of quality of life (Pain and Difficulties with treatment; $p<0.05$ ) and positively with coping strategies (Avoidance of problems; $\mathrm{p}<0.01$ ) (Table 3).

When comparing the two populations in terms of HIV and HCV coinfection, there were significant differences ( $p$ $<0.05$ ) in the perception of illness (Personal control, Illness Coherence and Emotional representation) and perception of quality of life (Satisfaction with treatment and Emotional Functioning). Similarly, in patients with hemophilia and HCV infection, we found significant differences ( $p<0.05$ ) between the two populations in perception of disease (Personal control, Illness Coherence and Emotional representation) and perception of quality of life (Satisfaction with treatment and Emotional Functioning) (Table 4).

\section{Discussion}

The largest differences when comparing samples from a clinical perspective were found in joint condition,

Table I Demographic and Clinical Characteristics of Hemophilia Patients in Two Different Countries

\begin{tabular}{|c|c|c|c|c|c|}
\hline \multirow[t]{2}{*}{ Variables } & \multicolumn{2}{|c|}{ Salvador Sample $(n=22)$} & \multicolumn{2}{|c|}{ Spanish Sample $(n=2 I)$} & \multirow[t]{2}{*}{ Sig. } \\
\hline & Mean (SD) & Range & Mean (SD) & Range & \\
\hline Age (years) & $29.36(8.31)$ & $18-48$ & $34.19(8.73)$ & $18-50$ & 0.07 \\
\hline Weight $(\mathrm{kg})$ & $73.36(5.87)$ & 63-85 & $75.00(6.30)$ & 64-84 & 0.38 \\
\hline Height $(\mathrm{cm})$ & $171.50(7.30)$ & $153-182$ & $175.67(5.09)$ & $166-184$ & $0.03 *$ \\
\hline HJHS total score $(0-124)$ & $35.36(21.40)$ & $13-86$ & $22.86(11.76)$ & $6-47$ & $0.02 *$ \\
\hline Hospital visits/year (number) & $13.55(5.82)$ & $7-30$ & $4.37(3.68)$ & $1-12$ & $0.00 * * *$ \\
\hline \multirow[t]{2}{*}{ Distance from hospital $(\mathrm{km})$} & $29.86(19.46)$ & $3-85$ & $21.57(21.87)$ & $2-60$ & 0.19 \\
\hline & $\mathbf{n}$ & $\%$ & $\mathbf{n}$ & $\%$ & \\
\hline Type of hemophilia (A/B) & $22 / 0$ & $100 / 0$ & 19/2 & $90.5 / 9.5$ & 0.14 \\
\hline Severity (Severe/Moderate) & $19 / 3$ & $86.4 / 13.6$ & $15 / 6$ & $71.4 / 28.6$ & $0.00^{* *}$ \\
\hline Treatment (Prophylaxis/On demand) & $0 / 22$ & $0 / 100$ & $5 / 16$ & $23.8 / 76.2$ & $0.01 *$ \\
\hline Self-treatment (Yes/No) & $7 / 15$ & $31.8 / 68.2$ & $9 / 12$ & $42.9 / 57.1$ & 0.46 \\
\hline Development of inhibitor (Yes/No) & $1 / 21$ & $4.5 / 95.5$ & $1 / 20$ & $4.8 / 95.2$ & 0.97 \\
\hline Coinfections ( $\mathrm{HIV}$ and $\mathrm{HCV} / \mathrm{HCV} / \mathrm{No}$ ) & $2 / 12 / 8$ & $9.1 / 54.5 / 36.4$ & $8 / 6 / 7$ & $38.1 / 28.6 / 33.3$ & 0.07 \\
\hline Orthosis (Yes/No) & $15 / 7$ & $68.2 / 31.8$ & $0 / 21$ & $0 / 100$ & $0.00 * *$ \\
\hline Academic training (University/Secondary/Primary) & $1 / 10 / 11$ & $4.5 / 45.5 / / 50.0$ & $6 / 11 / 4$ & $28.6 / 52.4 / 19.0$ & $0.00^{* *}$ \\
\hline Employment (Self-Employed/Employee/Unemployed) & $2 / 11 / 9$ & $9.1 / 50 / 40.9$ & $5 / 6 / 9 / 1$ & 23.8/28.6/42.9/4.8 & 0.89 \\
\hline Marital status (Married/Divorced/Single) & $7 / 15$ & $31.8 / 68.2$ & $10 / 11$ & $47.6 / 52.4$ & 0.30 \\
\hline
\end{tabular}

Notes: ${ }^{*} p<0.05 ; *_{p}<0.01 ; * * * p<0.001$.

Abbreviations: HJHS, Hemophilia Joint Health Score; HIV, human immunodeficiency virus; HCV, hepatitis C virus; Sig., signification; SD, standard deviation. 
Table 2 Perception of Illness, Quality of Life and Coping Strategy in Patients with Hemophilia

\begin{tabular}{|c|c|c|c|c|c|}
\hline \multirow[t]{2}{*}{ Variable } & \multirow[t]{2}{*}{ Item } & \multicolumn{2}{|c|}{ Mean (SD) } & \multicolumn{2}{|c|}{ t-test } \\
\hline & & El Salvador & Spain & $\mathbf{t}$ & Sig. \\
\hline \multirow[t]{7}{*}{ Illness Perception } & Identity & $6.09(2.38)$ & $4.76(2.64)$ & -1.73 & 0.09 \\
\hline & Consequences & $23.50(3.66)$ & $19.24(3.96)$ & -3.66 & $0.00 * *$ \\
\hline & Personal control & $22.18(3.66)$ & $35.95(38.26)$ & 1.68 & 0.10 \\
\hline & Treatment control & $19.59(2.32)$ & $20.24(3.52)$ & 0.71 & 0.47 \\
\hline & Illness Coherence & I6.05 (4.66) & $28.19(28.27)$ & 1.98 & 0.05 \\
\hline & Cycles of Illness & $16.27(2.5 \mathrm{I})$ & II.38 (2.29) & -6.66 & $0.00 * * *$ \\
\hline & Emotional representation & $20.59(5.65)$ & I4.52 (4.8I) & -3.78 & $0.00 * * *$ \\
\hline \multirow[t]{10}{*}{ Quality of life } & Physical health & $15.18(5.98)$ & $21.90(7.75)$ & 3.19 & $0.00 * *$ \\
\hline & Daily activities & $6.59(3.87)$ & $11.10(5.07)$ & 3.27 & $0.00 * *$ \\
\hline & Joints & $4.68(2.73)$ & $7.33(3.39)$ & 2.82 & $0.00 * *$ \\
\hline & Pain & $2.82(2.13)$ & $4.90(2.59)$ & 2.90 & $0.00 * *$ \\
\hline & Satisfaction with treatment & $5.23(1.63)$ & $6.29(2.79)$ & 1.52 & 0.13 \\
\hline & Difficulties with treatment & $7.23(3.53)$ & I0.7| (2.49) & 3.72 & $0.00 * *$ \\
\hline & Emotional functioning & $10.00(4.28)$ & $|4.8|(4.46)$ & 3.60 & $0.00 * *$ \\
\hline & Mental health & $5.86(2.71)$ & $9.38(3.41)$ & 3.75 & $0.00 * *$ \\
\hline & Social activities and relationships & II.50 (4.39) & $16.24(5.01)$ & 3.30 & $0.00 * *$ \\
\hline & Total A-36 & $69.14(20.37)$ & $102.67(20.74)$ & 4.33 & $0.00 * * *$ \\
\hline \multirow[t]{8}{*}{ Coping Strategies } & Problem solving & I3.55 (5.66) & $14.33(5.35)$ & 0.46 & 0.64 \\
\hline & Self-criticism & $7.91(5.46)$ & $4.67(4.92)$ & -2.04 & $0.04 *$ \\
\hline & Emotional expression & $9.27(5.93)$ & $6.95(4.96)$ & -1.38 & 0.17 \\
\hline & Deliberative thinking & $12.59(6.44)$ & $11.14(4.70)$ & -0.83 & 0.40 \\
\hline & Social support & $12.32(4.49)$ & $10.90(5.21)$ & -0.95 & 0.34 \\
\hline & Cognitive restructuring & $12.36(5.06)$ & $12.52(4.54)$ & 0.10 & 0.91 \\
\hline & Avoidance of problems & $10.77(4.84)$ & $9.48(4.22)$ & -0.93 & 0.35 \\
\hline & Social withdrawal & $8.45(4.14)$ & $6.05(3.98)$ & -1.94 & 0.05 \\
\hline
\end{tabular}

Notes: $*_{p}<0.05 ; *_{p}<0.01 ; * * * p<0.001$.

Abbreviations: SD, standard deviation; Sig., significance.

while damage to knees, ankles and elbows, and use of orthoses was greater in patients from El Salvador, which meant more frequent visits to the Hospital, with the disadvantage of the further traveling distance. These differences may be largely due to the difficulty in accessing substitution factor concentrates. Most Salvadoran patients were found to be on demand treatment. However, in comparing the psychosocial aspects (perception of disease and coping strategies), not such obvious differences were found. This is not so when we assess quality of life.

Lamiani et $\mathrm{al}^{19}$ found a connection between the target health status and the cognitive representation of the disease. Patients with poorer perception of their health showed poorer cognitive representations of their disease. In our study, a greater perception of the consequences, disease cyclicity and a strong negative representation of emotions, also relate to a poorer quality of life. Llewellyn et al and Reynolds et $\mathrm{al}^{18,20}$ assert that an adequate mental representation of the disease is associated with a better perception of health and self-care, together with a more effective management of the disease.

Patients with chronic pain often experience psychological problems, functional disabilities, and a poorer perception of quality of life. ${ }^{35}$ Our study found that patients from El Salvador present greater damage and joint pain, and a poorer perception of quality of life in almost all domains. This is consistent with other studies whereby it is acknowledged that pain generates poor quality of life in patients with hemophilia A, not only physically but mentally, which has an impact on their wellbeing. ${ }^{28,36,37}$

However, it should be noted that no differences were found in terms of satisfaction with treatment, taking into account the physical condition and access to treatment. Perhaps the psychological resources and defense mechanisms of patients are conditioning this response, and not so much the objective aspects of the situation. In addition, 
Table 3 Correlation Between Psychological Variables and Joint Status and Age of Patients with Hemophilia

\begin{tabular}{|c|c|c|c|c|c|}
\hline \multirow[t]{2}{*}{ Variable } & \multirow[t]{2}{*}{ Item } & \multicolumn{2}{|c|}{ Joint Status (HJHS) } & \multicolumn{2}{|c|}{ Age } \\
\hline & & El Salvador & Spain & EI Salvador & Spain \\
\hline \multirow[t]{7}{*}{ Illness Perception } & Identity & -0.10 & -0.18 & -0.13 & -0.33 \\
\hline & Consequences & -0.36 & 0.01 & -0.15 & -0.00 \\
\hline & Personal control & -0.29 & -0.30 & -0.21 & -0.07 \\
\hline & Treatment control & 0.00 & -0.11 & -0.15 & -0.18 \\
\hline & Illness Coherence & -0.06 & 0.09 & -0.15 & -0.01 \\
\hline & Cycles of Illness & -0.10 & $-0.50^{*}$ & -0.00 & $-0.64 * *$ \\
\hline & Emotional representation & 0.20 & -0.02 & 0.30 & -0.09 \\
\hline \multirow[t]{10}{*}{ Quality of life } & Physical health & -0.06 & $-0.49 *$ & -0.18 & -0.28 \\
\hline & Daily activities & 0.18 & -0.05 & 0.02 & 0.13 \\
\hline & Joints & 0.03 & -0.22 & -0.11 & 0.03 \\
\hline & Pain & -0.37 & -0.15 & $-0.49 *$ & 0.00 \\
\hline & Satisfaction with treatment & 0.13 & $-0.43^{*}$ & -0.04 & -0.40 \\
\hline & Difficulties with treatment & -0.42 & -0.11 & $-0.45^{*}$ & -0.08 \\
\hline & Emotional functioning & 0.33 & -0.15 & 0.14 & 0.00 \\
\hline & Mental health & 0.16 & -0.04 & -0.12 & 0.04 \\
\hline & Social activities and relationships & 0.11 & 0.08 & -0.09 & 0.18 \\
\hline & Total A-36 & 0.03 & -0.24 & -0.20 & -0.05 \\
\hline \multirow[t]{8}{*}{ Coping Strategies } & Problem solving & 0.13 & $-0.49 *$ & 0.31 & $-0.43 *$ \\
\hline & Self-criticism & -0.01 & -0.35 & -0.01 & -0.34 \\
\hline & Emotional expression & $0.43 *$ & -0.00 & 0.34 & -0.03 \\
\hline & Deliberative thinking & -0.11 & -0.20 & -0.06 & -0.29 \\
\hline & Social support & -0.06 & -0.21 & -0.08 & -0.34 \\
\hline & Cognitive restructuring & 0.31 & 0.01 & 0.38 & 0.14 \\
\hline & Avoidance of problems & 0.37 & -0.03 & $0.62 * *$ & 0.16 \\
\hline & Social withdrawal & -0.03 & -0.14 & -0.00 & -0.08 \\
\hline
\end{tabular}

Notes: ${ }^{*} \mathrm{p}<0.05 ; *^{*} \mathrm{p}<0.01$

interventions aimed at accepting chronicity and promoting well-being may be much more effective than merely evaluating the physical aspects. This is consistent with recent studies, which support the need to evaluate the degree of acceptance of the disease, the position it occupies in the patient's life, and consequently their favorable response or otherwise to health professionals' instructions regarding treatment. ${ }^{19,38,39}$

Prophylaxis is the gold standard in the treatment of patients with hemophilia, reducing the risk of joint bleeding and thus hemophilic arthropathy, the main predictor of quality of life in patients with severe hemophilia. ${ }^{40}$ Relevant variables in our study were joint damage, hemophilia severity and type of treatment.

Upon analyzing joint damage in knees, ankles and elbows, Spanish patients were found to have a greater perception of cyclicity, a poorer perception of their physical health and also greater difficulties with the treatment. However, the joint condition of the Salvadoran patients was not related to perception of the disease or quality of life assessment, yet to a high emotional expression as a coping strategy.

With respect to age, younger patients in the Salvadoran sample showed many limitations in their quality of life based on the pain and problems with the treatment. Young Spanish patients perceived greater cyclicity of the disease, which is consistent with Elander's theory, ${ }^{28}$ whereby it is essential to address the acceptance of pain in order to manage it, and more so when there are differences in terms of access to factor concentrates. It should be noted that pain affects the perception of the disease and treatment experiences and impacts on quality of life. Therefore, importantly, patients with hemophilia should be taught to manage the disease from a holistic perspective, which allows them to face the challenges, without reducing their quality of life, despite socio-demographic circumstances. 
Table 4 Univariate Analysis of the Dependent Variables, with Respect to the Country of Origin and HIV and HCV Infections

\begin{tabular}{|c|c|c|c|c|c|c|c|}
\hline \multirow[t]{2}{*}{ Variable } & \multirow[t]{2}{*}{ Item } & \multicolumn{2}{|c|}{$\mathrm{HIV}$ and $\mathrm{HCV}$} & \multicolumn{2}{|c|}{$\mathrm{HCV}$} & \multicolumn{2}{|c|}{ No Infections } \\
\hline & & El Salvador & Spain & El Salvador & Spain & El Salvador & Spain \\
\hline Illness Perception & $\begin{array}{l}\text { Identity } \\
\text { Consequences } \\
\text { Personal control } \\
\text { Treatment control } \\
\text { Illness Coherence } \\
\text { Cycles of Illness } \\
\text { Emotional representation }\end{array}$ & $\begin{array}{c}3.00(2.82) \\
20.50(3.53) \\
23.50(0.70)^{* *} \\
19.00(0.00) \\
13.50(2.12) \\
15.00(2.82) \\
21.50(2.12)^{* *}\end{array}$ & $\begin{array}{c}4.37(2.87) \\
21.38(5.12) \\
18.63(4.56) \\
18.75(4.16) \\
15.50(4.75)^{*} \\
10.37(3.15) \\
17.13(3.52)\end{array}$ & $\begin{array}{c}6.58(2.27) \\
23.58(4.10) \\
21.67(3.86) \\
19.25(2.52) \\
15.25(4.57) \\
16.17(2.51) \\
21.75(6.45)^{* *}\end{array}$ & $\begin{array}{c}3.83(3.12) \\
16.83(2.99) \\
74.17(57.89)^{* *} \\
23.17(1.47) \\
53.33(45.44)^{*} \\
11.33(0.51) \\
8.83(3.06)\end{array}$ & $\begin{array}{l}6.13(2.16) \\
24.12(2.99) \\
22.63(3.92) \\
20.25(2.31) \\
17.88(4.99) \\
16.75(2.65) \\
18.63(4.77)\end{array}$ & $\begin{array}{l}6.00(1.63) \\
18.86(1.46) \\
23.00(2.64) \\
19.43(2.63) \\
21.14(3.53) \\
12.57(1.61) \\
16.43(3.04)\end{array}$ \\
\hline Quality of life & $\begin{array}{l}\text { Physical health } \\
\text { Daily activities } \\
\text { Joints } \\
\text { Pain } \\
\text { Satisfaction with treatment } \\
\text { Difficulties with treatment } \\
\text { Emotional functioning } \\
\text { Mental health } \\
\text { Social activities and relationships } \\
\text { Total A-36 }\end{array}$ & $\begin{array}{c}16.50(9.19) \\
9.50(6.36) \\
3.50(2.12) \\
1.00(1.41) \\
7.50(0.70)^{* *} \\
1.50(2.12) \\
14.00(5.65)^{*} \\
7.00(5.65) \\
14.50(7.77) \\
75.00(32.52)\end{array}$ & $\begin{array}{c}16.38(7.15) \\
9.75(6.15) \\
6.25(3.45) \\
4.25(2.81) \\
4.75(3.28) \\
10.38(3.33) \\
11.88(4.85) \\
7.63(4.40) \\
14.38(6.07) \\
85.63(33.05)\end{array}$ & $\begin{array}{c}14.50(6.78) \\
5.67(3.67) \\
4.42(3.02) \\
2.67(2.67) \\
4.42(1.31) \\
7.67(3.22) \\
10.33(4.29) \\
5.42(2.64) \\
11.00(4.26) \\
66.17(21.30)\end{array}$ & $\begin{array}{c}26.50(7.45) \\
13.50(3.50) \\
8.83(3.92) \\
5.67(2.94) \\
8.33(0.81)^{* *} \\
10.50(1.97) \\
18.83(1.32)^{*} \\
11.83(0.40) \\
20.00(0.00) \\
124.00(20.66)\end{array}$ & $\begin{array}{c}15.88(4.61) \\
7.25(3.69) \\
5.38(2.50) \\
3.50(0.75) \\
5.88(1.45) \\
8.00(3.16) \\
8.50(3.78) \\
6.25(2.37) \\
11.50(4.20) \\
72.13(18.59)\end{array}$ & $\begin{array}{c}24.29(5.09) \\
10.57(4.79) \\
7.29(2.81) \\
5.00(2.08) \\
6.29(2.36) \\
11.29(1.97) \\
14.71(3.14) \\
9.29(2.43) \\
15.14(4.52) \\
103.86(21.77)\end{array}$ \\
\hline Coping Strategies & $\begin{array}{l}\text { Solving problems } \\
\text { Self-criticism } \\
\text { Emotional expression } \\
\text { Deliberative thinking } \\
\text { Social support } \\
\text { Cognitive restructuring } \\
\text { Avoidance of problems } \\
\text { Social withdrawal }\end{array}$ & $\begin{array}{l}13.50(3.53) \\
7.00(1.4 \mid) \\
14.00(5.65) \\
6.50(3.53) \\
10.00(7.07) \\
13.00(1.41) \\
11.50(4.95) \\
6.00(4.24)\end{array}$ & $\begin{array}{l}10.38(4.77) \\
4.25(4.20) \\
5.00(4.10) \\
8.88(3.35) \\
7.38(3.58) \\
10.13(1.55) \\
7.63(2.38) \\
6.38(4.53)\end{array}$ & $\begin{array}{c}15.08(4.58) \\
8.08(5.58) \\
10.08(5.36) \\
13.58(6.15) \\
12.33(4.73) \\
13.17(5.409) \\
12.58(5.10) \\
8.58(3.34)\end{array}$ & $\begin{array}{l}20.00(0.00) \\
0.67(1.63) \\
8.00(6.66) \\
12.83(6.55) \\
12.83(6.55) \\
18.33(1.50) \\
14.33(1.96) \\
4.17(1.32)\end{array}$ & $\begin{array}{l}11.25(7.16) \\
7.88(6.33) \\
6.88(6.44) \\
12.63(7.15) \\
12.88(4.05) \\
11.00(5.23) \\
7.88(3.27) \\
8.88(5.43)\end{array}$ & $\begin{array}{l}14.00(3.95) \\
8.57(4.89) \\
8.29(4.15) \\
12.29(3.68) \\
13.29(3.59) \\
10.29(4.11) \\
7.43(4.07) \\
7.29(4.68)\end{array}$ \\
\hline
\end{tabular}

Notes: ${ }^{*} \mathrm{p}<0.05 ; *^{*} \mathrm{p}<0.01$.

Abbreviations: HIV, human immunodeficiency virus; HCV, hepatitis $\mathrm{C}$ virus.

$\mathrm{HIV} / \mathrm{HCV}$ infection in previous decades increased the percentage of comorbidity and mortality in patients with hemophilia in adulthood. ${ }^{41}$ Torres-Ortuño et $\mathrm{al}^{42}$ established that patients infected with HIV or HCV did not show significant differences when analyzing disease behavior compared to non-infected subjects. Theorell et $\mathrm{al}^{43}$ stated that an alteration of the emotional state can adversely affect the immune status of patients with hemophilia and HIV. Hence, a positive emotional state and adaptive behavior to the disease can be very useful in improving coping strategies and adherence to medical treatments.

Our study only revealed differences when we analyzed the group of patients infected with $\mathrm{HCV}$, in terms of quality of life and perception of the disease, when comparing the Spanish and Salvadoran samples. However, no significant differences were found when analyzing coping strategies, suggesting that, irrespective of the objective health data, the importance of patient coping resources is a good predictor for the control and management of the disease.
Adult patients with hemophilia have shown to better adapt to the disease than young patients. ${ }^{44}$ According to Lamiani et al, ${ }^{19}$ adolescents and young people find it more difficult to cope with complications related to the disease, due to their lack of experience with symptoms, mainly in relation to prophylactic treatment. Our study found that older Salvadoran patients had a better perception of joint pain, less difficulties with treatment, and greater use of avoidance of problems as coping mechanisms, in order to counteract deficiencies, mainly related to treatment. On the other hand, younger patients in the Spanish sample were found to present a poorer perception of the disease cycles and hardly used problem solving strategies.

\section{Limitations of the Study}

Although this is the first study to analyze the relationship between clinical and psychosocial factors in patients with hemophilia of countries with such different levels of access to pharmacological treatment, several limitations need to be considered. This study has been carried out 
by recruiting a small sample, so the statistical power of our tests may be relatively low. Similarly, the possible statistical error (type II) should be taken into account as a result of our analysis not showing significant relationships between variables that are actually important.

\section{Relevance to Clinical Practice}

The management of psychosocial factors in patients with hemophilia has been shown to be a very effective tool, even in cases of difficult access to pharmacological treatments, as is the case of Salvadoran patients.

\section{Conclusions}

Hemophiliacs with reduced access to prophylactic treatments present a poorer joint condition. The perception of quality of life and the perception of disease were significantly poorer in patients with hemophilia from El Salvador, compared to those living in Spain. Despite the differences in level of access to treatment between the two countries, there are no differences in terms of coping with the disease. The age variable plays a prominent role in how patients adapt to the disease situation.

\section{Acknowledgments}

The authors wish to thank health professionals and patients from El Salvador for their participation, collaboration and favorable response to this project; the example they set and their everyday struggle strongly motivate our continued work for patients with hemophilia. The authors are especially grateful to the Fundación Novo Nordisk for their support in the twinning program.

\section{Disclosure}

The authors state they have no interests that might be perceived as posing a conflict or bias for this work.

\section{References}

1. Ljung R, Gretenkort Andersson N. The current status of prophylactic replacement therapy in children and adults with haemophilia. $\mathrm{Br}$ J Haematol. 2015;169(6):777-786. doi:10.1111/bjh.13365

2. Flood E, Pocoski J, Michaels LA, Bell JA, Valluri S, Sasanè R. Illustrating the impact of mild/moderate and severe haemophilia on health-related quality of life: hypothesised conceptual models. Eur J Haematol. 2014;93(75):9-18. doi:10.1111/ejh.12328

3. Pulles AE, Mastbergen SC, Schutgens REG, Lafeber FPJG, van Vulpen LFD. Pathophysiology of hemophilic arthropathy and potential targets for therapy. Pharmacol Res. 2017;115:192-199. doi:10.1016/j. phrs.2016.11.032

4. Tagliaferri A, Feola G, Molinari AC, et al. Benefits of prophylaxis versus on-demand treatment in adolescents and adults with severe haemophilia A: the POTTER study. Thromb Haemost. 2015;114 (07):35-45. doi:10.1160/TH14-05-0407
5. Hoots WK, Shapiro AD. Inhibitors in hemophilia: mechanisms, prevalence, diagnosis, and eradication. In: Post TW, editor. UpToDate. Waltham, MA: UpToDate Inc; 2020.

6. Djerassi I, Bhanchet P, Hsies Y, Wolman IJ. Clinical use of cold precipitated antihemophilic globulin (factor VIII, CPAG). Transfusion. 1965;5:533-538. doi:10.1111/j.1537-2995.1965. tb01200.x

7. Lee CA, Kernoff PBA. Blood Product Therapy in Haemophilia: Historic Papers. London: Science Press; 1986.

8. Colvin BT. Haemophilia in the UK. Past, present and future. Haemophilia. $\quad$ 1995;1(S2):4-5. doi:10.1111/j.1365-2516.1995. tb00113.x

9. Isarangkura P. Haemophilia care in the developing world: benchmarking for excellence. Haemophilia. 2002;8:205-210. doi:10.1046/ j.1365-2516.2002.00600.x

10. Mannucci PM, Schutgens RE, Santagostino E, Mauser-Bunschoten EP. How I treat age-related morbidities in elderly persons with hemophilia. Blood. 2009;114:5256-5263. doi:10.1182/blood-200907-215665

11. Konkle BA. Clinical challenges within the aging hemophilia population. Thromb Res. 2011;127(1):S10-3. doi:10.1016/j. thromres.2010.10.004

12. O'Mahnony B. Global haemophilia care. Haemophilia. 2000;6 (2): $1-2$.

13. Rickard KA. The International Haemophilia Training Centres of the World Federation of Hemophilia: a 30-year review. Haemophilia. 2000;6:471-473. doi:10.1046/j.1365-2516.2000.00446.x

14. World Federation of Hemophilia. Report on the WFH Global Survey on Hemophilia 2001 for National Member Organization. 2001.

15. Shumaker SA, Naughton MJ. The international assessment of health related quality of life: a theoretical perspective. In: Shumaker SA, Berzon RA, editors. The International Assessment of Health Related Quality of Life. Theory, Translation, Measurement and Analysis. New York: Rapid Communication; 1995:3-10.

16. Leventhal H, Benyamini Y, Brownlee S. Illness representations: theoretical foundations. In: Petrie KJ, Weinman J, editors. Perceptions of Health and Illness: Current Research and Applications. Amsterdam: Harwood Academic Publishers; 1997:19-45.

17. Leventhal H, Diefenbach MA, Leventhal EA. Illness cognition: using common sense to understand treatment adherence and affect cognition interactions. Cognit Ther Res. 1992;16:143-163. doi:10.1007/ BF01173486

18. Llewellyn C, Minersb A, Leec A, Harrington C, Weinman J. The illness perceptions and treatment beliefs of individuals with severe haemophilia and their role in adherence to home treatment. Psychol Health. 2003;18:185-200. doi:10.1080/0887044031000098198

19. Lamiani G, Strada I, Mancuso ME, Coppola A, Vegni E, Moja EA. Factors influencing illness representations and perceived adherence in haemophilic patients: a pilot study. Haemophilia. 2015;21:598-604. doi:10.1111/hae.12654

20. Reynolds NR, Eller LS, Nicholas PK, et al. HIV illness representation as a predictor of self-care management and health outcomes: a multi-site, cross-cultural study. AIDS Behav. 2009;13:258-267. doi:10.1007/s10461-007-9297-5

21. Coppola A, Cerbone AM, Mancuso G, Mansueto MF, Mazzini C, Zanon E. Confronting the psychological burden of haemophilia. Haemophilia. 2011;17:21-27. doi:10.1111/j.1365-2516.2010.02280.x

22. Cassis FY, Querol F, Forsyth A, Iorio A. Psychosocial aspects of haemophilia: a systematic review of methodologies and findings. Haemophilia. 2012;18(3):e101-e114. doi:10.1111/j.13652516.2011.02683.x

23. Urzua A, Jarne N. Quality of life and coping styles in people with chronic diseases. Interam J Psychol. 2008;42:151-160.

24. Sarafino EP. Health Psychology: Biopsychological Interactions. Wiley: New York; 2008. 
25. Bottos AM, Zanon E, Sartori MT, Girolami A. Psychological aspects and coping styles of parents with Haemophilic child undergoing a programme of counseling and psychological support. Haemophilia. 2007;13:305-310. doi:10.1111/j.13652516.2006.01428.x

26. Wiedebusch S, Pollmann H, Siegmund B, Muthny FA. Quality of life, psychosocial strains and coping in parents of children with haemophilia. Haemophilia. 2008;14:1014-1022. doi:10.1111/j.13652516.2008.01803.x

27. Canclini M, Saviolo-Negrin N, Zanon E, Bertoletti R, Girolami A, Pagnan A. Psychological aspects and coping in haemophilic patients: a case-control study. Haemophilia. 2003;9:619-624. doi:10.1046/ j.1365-2516.2003.00807.x

28. Elander J, Morris J, Robinson G. Pain coping and acceptance as longitudinal predictors of health-related quality of life among people with haemophilia-related joint pain. Eur J Pain. 2013;17:929-938. doi:10.1002/j.1532-2149.2012.00258.x

29. Binnema M, Schrijvers LH, Bos R, Schuurmans MJ, Fischer K. Coping in adult patients with severe haemophilia. Haemophilia. 2014;20:513-518. doi:10.1111/hae.12366

30. Brodin E, Baghaei F, Sunnerhagen KS. Self-reported activity and functioning in daily life; the perspective of persons with haemophilia living in Sweden. Eur J Haematol. 2015;95(4):336-341. doi:10.1111/ ejh. 12503

31. Pacheco-Huergo V, Viladrich C, Pujol-Ribera E, et al. Perception in chronic illnesses: linguistic validation of the revised Illness Perception Questionnaire and the Brief Illness Perception Questionnaire for a Spanish population. Aten Primaria. 2012;44 (5):280-287. doi:10.1016/j.aprim.2010.11.022

32. Remor E, Arranz P, Quintana M, et al. Psychometric field study of the new haemophilia quality of life questionnaire for adults: the 'Hemofilia-QoL'. Haemophilia. 2005;11(6):603-610. doi:10.1111/ j.1365-2516.2005.01144.x

33. Cano-García FJ, Rodríguez-Franco L, García-Martínez J. Spanish adaptation of the inventory of coping strategies. Actas Esp Psiquiatr. 2007;35(1):29-39.

34. Feldman BM, Funk SM, Bergstrom BM, et al. Validation of a new paediatric joint scoring system from the International Hemophilia Prophylaxis Study Group: validity of the hemophilia joint health score. Arthritis Care Res. 2011;63(2):223-230. doi:10.1002/ acr.20353
35. Witkop M, Neff A, Buckner TW, et al. Self-reported prevalence, description and management of pain in adults with haemophilia: methods, demographics and results from the Pain, Functional Impairment, and Quality of life (P-FiQ) study. Haemophilia. 2017;23(4):556-565. doi:10.1111/hae.13214

36. Solovieva S. Clinical severity of disease, functional disability and health-related quality of life. Three-year follow-up study of 150 Finnish patients with coagulation disorders. Haemophilia. 2001;7:53-63.

37. Fischer K, Van der Bom JG, Mauser-Bunschoten EP, Roosendaal G, Van den Berg HM. Effects of haemophilic arthropathy on health-related quality of life and socioeconomic parameters. Haemophilia. 2005;11:43-48. doi:10.1111/j.1365-2516.2005.01065.x

38. Schrijvers LH, Schuurmans MJ, Fischer K. Promoting self-management and adherence during prophylaxis: evidence-based recommendations for haemophilia professionals. Haemophilia. 2016;22(4):499-506. doi:10.1111/hae.12904

39. Torres-Ortuño A, Cid-Sabatel R, Garcia-Dasi M, Barrero J. Life experience of the adult and ageing patient with haemophilia. Practical aspects for psychological support. Vox Sang. 2017;112 (4):301-309. doi:10.1111/vox.12501

40. Srivastava A, Santagostino E, Dougall A, et al. WFH guidelines for the management of hemophilia, 3rd edition. Haemophilia. 2020;26 (S6):1-158. doi:10.1111/hae.14046

41. Katsarou O, Touloumi G, Antoniou A, Kouramba A, Hatzakis A, Karafoulidou A. Progression of HIV infection in the post-HAART era among a cohort of HIV+ Greek haemophilia patients. Haemophilia. 2005;11(4):360-365. doi:10.1111/j.1365-2516.2005.01109.x

42. Torres-Ortuño A, Cuesta-Barriuso R, Nieto-Munuera J. The influence of HIV, HCV and inhibitors on the quality of life and behavior of the disease in patients with haemophilia: an observational study. J AIDS Clin Res. 2016;7(1):534.

43. Theorell T, Blomkvist V, Jonsson H, Schulman S, Berntorp E, Stigendal L. Social support and the development of immuno function in human immunodeficiency virus infection. Psychosom Med. 1995;57:32-36. doi:10.1097/00006842-199501000-00005

44. Osooli M, Steen Carlsson K, Baghaei F, et al. The association between health utility and joint status among people with severe haemophilia A: findings from the KAPPA register. Haemophilia. 2017;23:e180-e187. doi:10.1111/hae.13231
Patient Preference and Adherence

\section{Publish your work in this journal}

Patient Preference and Adherence is an international, peer-reviewed, open access journal that focusing on the growing importance of patient preference and adherence throughout the therapeutic continuum. Patient satisfaction, acceptability, quality of life, compliance, persistence and their role in developing new therapeutic modalities and compounds to optimize clinical outcomes for existing disease states are major areas of interest for the journal. This journal has been accepted for indexing on PubMed Central. The manuscript management system is completely online and includes a very quick and fair peer-review system, which is all easy to use. Visit http:// www.dovepress.com/testimonials.php to read real quotes from published authors. 